\title{
ANÁLISE COMPARATIVA DA ESCALA RSQ (RETAIL SERVICE QUALITY) EM DIFERENTES FORMATOS VAREJISTAS
}

\author{
1- Sérgio Silva Braga Júnior* \\ Doutorando em Administração pela Universidade Nove de Julho (UNINOVE), Brasil. \\ sergio.bragajunior@gmail.com \\ http://lattes.cnpq.br/0079705864432706
}

\section{2- Evandro Luiz Lopes}

Doutor em Administração pela Universidade Nove de Julho (UNINOVE), Brasil.

Professor titular do Programa de Mestrado e Doutorado da Universidade Nove de Julho (UNINOVE), Brasil. elldijo@uol.com.br

http://lattes.cnpq.br/0631574435962669

\section{3- Dirceu da Silva}

Doutor em Educação pela Universidade de São Paulo (USP), Brasil.

Professor titular do Programa de Mestrado e Doutorado da Universidade Nove de Julho (UNINOVE), Brasil. dirceuds@uol.com.br

http://lattes.cnpq.br/9583759917108842

\section{4- Sergio Luiz do Amaral Moretti}

Doutor em Ciências Sociais pela Pontifícia Universidade Católica de São Paulo (PUC-SP), Brasil.

Professor titular do Programa de Mestrado e Doutorado da Universidade Nove de Julho (UNINOVE), Brasil. smoretti@uol.com.br

http://lattes.cnpq.br/1686957518540720

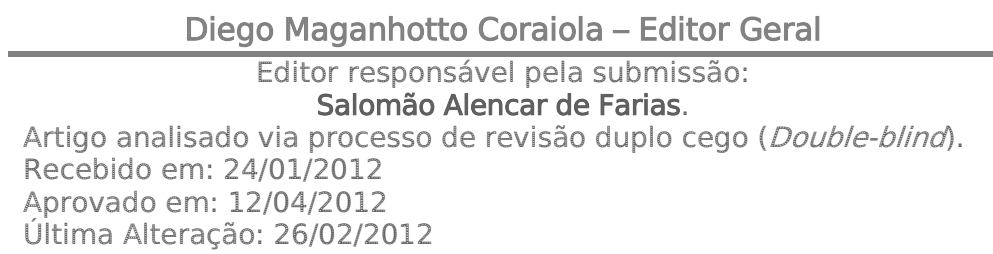

\footnotetext{
* Contato Principal: Universidade Nove de Julho, PMDA -Programa de Mestrado e Doutorado em Administração. Av. Francisco Matarazzo, 612. São Paulo, SP - Brasil. CEP: 05001-972.
} 


\title{
ANÁLISE COMPARATIVA DA ESCALA RSQ (RETAIL SERVICE QUALITY) EM DIFERENTES FORMATOS VAREJISTAS
}

\section{RESUMO}

Apesar da qualidade percebida de serviços prestados por uma empresa ser um tema de grande interesse, tanto no meio acadêmico quanto no empresarial, parece que o mesmo está longe de ser esgotado. O grande número de investigações científicas nesta área não chega a surpreender, pois vários acadêmicos acreditam que a qualidade percebida é um dos principais antecedentes da lealdade dos consumidores. Entendendo ainda existirem lacunas nas escalas de medição de qualidade do serviço, Dabholkar, Thorpe e Rentz (1996) criaram e validaram uma escala com a amplitude necessária capaz de realizar a mensuração do construto em todos os segmentos varejistas a qual batizaram de RSQ - Retail Service Quality. Com o objetivo de demonstrar a aplicabilidade da escala RSQ no contexto brasileiro, foram realizados três surveys com 690 consumidores de estabelecimentos varejistas de diferentes formatos (serviços bancários, loja de material esportivo e loja de roupas) todos da cidade de São Paulo. A análise dos dados, por meio de modelagem de equações estruturais com matriz de estimação por mínimos quadrados parciais, indicou que a escala RSQ identificou as cinco dimensões teóricas da qualidade percebida e que possibilitou a verificação dos pontos de maior e menor relevância em cada formato varejista. Destacaram-se na análise dos dados os altos coeficientes de determinação para as dimensões Interações Pessoais e Confiança.

\section{Palavras-chave}

Qualidade percebida, retail service quality, varejo.

\section{COMPARATIVE ANALYSIS OF RSQ SCALE (RETAIL SERVICE QUALITY) IN DIFFERENT RETAILERS FORMATS}

\begin{abstract}
Despite the perceived quality of services provided by a company to be a topic of great interest, both in academia and business, it seems that the same is far from being exhausted. The large number of scientific research in this area is not enough to surprise, because many academics believe that the perceived quality is one of the main antecedents of consumer loyalty. Understanding there are still gaps in measurement scales of quality of service, Dabholkar, Thorpe and Rentz (1996) created and validated a scale with the breadth required to perform the measurement of the construct in all segments retailers which named RSQ Retail Service Quality. With the goal to demonstrate the applicability of scale RSQ in brazilian context surveys were carried out three with 690 consumers of three retail establishments of different formats. Data analysis, by means of structural equations modeling by partial least squares, indicated that the Scale RSQ identified the five theoretical dimensions of perceived quality and that enabled the verification of major and minor relevance in each retail format. High coefficients of determination for dimensions Personal Interactions and Trust stood out in data analysis.
\end{abstract}

\section{Keywords}

Perceived quality, retail service quality, retail. 


\section{Introdução ${ }^{1}$}

Mesmo sendo um tema clássico do estudo do comportamento do consumidor, a qualidade percebida ainda desperta o interesse de muitos acadêmicos, tanto no Brasil quanto no exterior. Uma pesquisa rápida realizada no website Schollar Google aponta para mais de 400 pesquisas acadêmicas brasileiras realizadas com este construto somente nos 3 últimos anos. Do mesmo modo, a base de dados EBSCO indica outros 984 papers publicados sobre esta temática no mesmo período ${ }^{1}$.

O grande número de investigações científicas nesta área não chega a surpreender, pois vários acadêmicos acreditam que a qualidade percebida é um dos principais antecedentes da lealdade dos consumidores (Parasuraman, Zeithaml, \& Berry, 1985; Cronin \& Taylor, 1992; Dabholkar, Thorpe, \& Rentz, 1996; Hong \& Goo, 2004).

Diante da consistente agenda de pesquisas estabelecida, grande parte dos estudos, teóricos e empíricos, está voltada para a identificação, desenvolvimento e aplicação de escalas psicométricas que possibilitem a mensuração, confiável e parcimoniosa, da qualidade percebida pelos consumidores. De fato, algumas delas são tidas como de ampla aplicação - SERVQUAL (Parasuraman, Zeithaml, \& Berry, 1988) e SERVPERF (Cronin \& Taylor, 1992), por exemplo - e outras concebidas para contextos específicos, como a escala SPS - Sales Performance Scale (Sujan, Weitz, \& Kimar, 1994) para vendas, a PDSQ - Physical Distribution Service Quality (Beinstock, Mentzer, \& Bird, 1997) para serviços de logística, a EXCEL Excellence in Business (Sharma, Netemeyer, \& Mahajan, 1990) para mensuração da excelência de serviços, além da RSQ - Retail Service Quality (Dabholkar, Thorpe, \& Rentz, 1996) que se propõe a mensurar a qualidade percebida em serviços no segmento varejista.

O principal objetivo deste estudo é realizar a análise comparativa da qualidade percebida de serviços em três formatos varejitas distintos e, com isto, identificar a relação entre a qualidade percebida e suas dimensões teóricas nos varejistas pesquisados. Além deste objetivo principal, também se espera demonstrar a aplicabilidade da escala RSQ no contexto brasileiro, pois mesmo que nos últimos quinze anos já se contem diversas aplicações da escala RSQ no cenário internacional, ela ainda permanece pouco difundida no Brasil. Para isto, este artigo está formatado em cinco partes incluindo esta breve seção introdutória. A segunda seção faz a revisão teórica da escala RSQ. A terceira seção comentará os aspectos metodológicos da etapa empírica do estudo. Na quarta seção, serão discutidos os resultados obtidos e, finalmente, na quinta seção são realizados os comentários finais.

\section{Revisão Teórica}

Pretende-se nesta seção fazer uma discussão crítica à respeito da concepção teórica da escala RSQ bem como comentar as principais aplicações empíricas dessa ferramenta.

\subsection{Modelo RSQ - Retail Service Quality}

Em 1996, Pratibha Dabholkar, Dayle Thorpe e Joseph Rentz entenderam que ainda existiam lacunas nas escalas de medição de qualidade do serviço, pois, segundo eles, ainda não havia uma escala com a amplitude necessária capaz de realizar a mensuração do construto em todos os segmentos de negócios.

Segundo esses autores, o ambiente competitivo no varejo está em constante mudança, pois tanto a intensificação da competição entre empresas domésticas e estrangeiras quanto o número de incorporações e aquisições são crescentes. Outro fato que apóia este pensamento é o aumento da exigência dos consumidores em geral. Diante deste cenário, os varejistas de hoje devem implementar estratégias de diferenciação, embasando suas ações no entendimento das necessidades e expectativas de seus clientes.

Esses pesquisadores concordam que a escala SERVQUAL é o instrumento mais "intensamente conhecido e aplicado" para mesurar a qualidade de serviços, entretanto, alegam que a escala foi testada empiricamente em um grande número de experimentos que envolviam empresas fornecedoras de serviços "puros", e que, portanto, a escala é mais robusta quando aplicada em empresas onde inexista, ao menos em grande escala, a comercialização de produtos físicos. Alegam ainda que o instrumento não havia sido adaptado com sucesso na aplicação em um ambiente da loja de varejo, que possui características diferentes daquelas encontradas em empresas de serviço puro. De fato, em empresas varejistas, os clientes percorrem a loja livremente fazendo seu próprio percurso, muitas vezes encontrando a mercadoria que querem de forma autônoma, interagindo com diversos funcionários da empresa, devolvendo e 
trocando mercadorias, entre outras características específicas que influenciam a avaliação da qualidade dos serviços sob a ótica dos clientes (Dabholkar, Thorpe, \& Rentz, 1996).

Embasados, então, na diferença existente entre lojas varejistas e demais fornecedores de serviços, Dabholkar, Thorpe e Rentz (1996) acreditam que no ambiente varejista faz-se necessário mensurar outras dimensões além daquelas apontadas pela escala SERVQUAL de Parasuraman, Zeithaml e Berry (1985, 1988).

Realmente, várias aplicações que utilizaram a SERVQUAL não identificaram as dimensões da qualidade propostas por seus criadores. Algumas delas são apontadas na Figura 1.

\begin{tabular}{|c|c|c|c|}
\hline Pesquisador & Aplicação & Metodologia & Resultados observados \\
\hline Carman (1990) & $\begin{array}{l}\text { Loja de pneus, escola } \\
\text { de odontologia, } \\
\text { hospital de tratamento } \\
\text { intensivo. }\end{array}$ & $\begin{array}{l}\text { Utilizou a escala SERVQUAL } \\
\text { modificada, aplicando entre } 12 \text { e } \\
22 \text { questões. }\end{array}$ & $\begin{array}{l}\text { O resultado foi significativo em } \\
\text { todas as aplicações, exceto na loja } \\
\text { de pneus - única em que a } \\
\text { comercialização de produtos } \\
\text { físicos era expressiva. }\end{array}$ \\
\hline Finn e Lamb (1991) & \begin{tabular}{ll} 
Quatro & \multicolumn{2}{l|}{ diferentes } \\
tipos de & lojas de \\
varejo. &
\end{tabular} & SERVQUAL original & $\begin{array}{l}\text { Não foi possível validar a escala } \\
\text { em nenhum dos casos estudados. }\end{array}$ \\
\hline $\begin{array}{l}\text { Guiry, Hutchinson e } \\
\text { Weitz (1992) }\end{array}$ & rejista & $\begin{array}{l}\text { SERVQUAL modificada, com } 51 \\
\text { pares de questões, sendo } 15 \\
\text { originais e outras } 36 \text { novas }\end{array}$ & $\begin{array}{l}\text { Validou um modelo } \\
\text { contemplava } 7 \text { dimensões e } \\
\text { apenas as } 5 \text { originais. }\end{array}$ \\
\hline
\end{tabular}

Figura 1: Aplicações da escala SERVQUAL no varejo

Fonte: Dabholkar, Thorpe e Rentz (1996).

Dabholkar, Thorpe e Rentz (1996) ressaltam o estudo realizado por Guiry, Hutchinson e Weitz (1992), que adaptaram as 22 questões da escala SERVQUAL, removendo 7 e incluindo outras 36 . A análise dos dados revelou sete dimensões para mensuração de qualidade no varejo: (1) atendimento; (2) variedade de produtos; (3) confiabilidade nas transações comerciais; (4) disponibilidade de pessoal para atendimento; (5) aspectos tangíveis; (6) confiabilidade na política de serviços da loja e (7) preço. Embora este estudo representasse um bom início para construção de uma escala de mensuração de qualidade no varejo, foi abandonado, pois a inclusão do preço como fator de explicação da qualidade não foi aceita pela academia, isso porque, muito embora o preço seja um determinante importante na escolha da loja, não há estudos que comprovem sua relação com a qualidade percebida de serviços.

Julgando ser necessário conceber uma escala que possibilitasse a mensuração da qualidade percebida de serviços varejistas, Dabholkar, Thorpe e Rentz (1996) iniciaram uma triangulação de pesquisas empíricas. Na primeira, através de entrevistas com consumidores na saída de lojas, buscaram identificar quais eram os atributos da qualidade relativos à experiência de compra em lojas varejistas, que fossem significativos para os clientes. Esse estudo mostrou que os clientes estavam muito interessados acerca da disposição física das lojas, pois eles próprios precisavam se movimentar pelos corredores e, muitas vezes, encontrar sozinhos os produtos desejados. Também havia grande interesse pelo tratamento recebido dos funcionários da loja, pelo conforto que esta proporcionava, pela política de aceitação de cartões de crédito e pela facilidade de troca ou devolução de produtos comprados.

Na segunda pesquisa, foram realizadas seis entrevistas em profundidade com frequentadores de lojas de varejo, visando descobrir outros atributos importantes que não haviam sido citados na primeira rodada de entrevistas. Vários atributos identificados na primeira pesquisa foram corroborados nessa rodada, entre eles a disposição dos corredores, o atendimento do pessoal da loja e a facilidade para devolver produtos. Entretanto, outros atributos também foram identificados: aparência agradável da loja e dos "facilitadores" (facilities, em inglês), tais como banheiros, provadores, estacionamentos, entre outros. Esses entrevistados também comentaram sobre a importância de que todas as promessas feitas pela loja fossem cumpridas.

Finalmente, a terceira etapa da triangulação qualitativa utilizou como técnica "seguir" os clientes dentro da loja e observar como eles se comportavam. Os entrevistados foram gravados enquanto caminhavam pelos corredores das lojas, quando interagiam com funcionários e com as mercadorias expostas. No momento em que decidiam adquirir algum produto, eles relatavam o que estavam pensando e o porquê de optarem por aquele produto e não outro. Os autores alegam que a experiência de compra e as interações dos clientes com os demais elementos do ambiente foram coletadas sem que houvesse alterações significativas do fluxo natural dos acontecimentos. Os participantes comentavam sobre a 
aparência da loja, sobre a disposição dos corredores, a disponibilidade e a qualidade do auxílio dos funcionários do varejista e sobre a qualidade dos produtos ofertados.

Combinando as descobertas realizadas durante a etapa exploratória coadunada aos pressupostos teóricos desenvolvidos até então, Dabholkar, Thorpe e Rentz (1996) conceberam uma estrutura hierárquica dos fatores que determinam a qualidade de serviço para o ambiente varejista. Da mesma forma que Parasuraman, Zeithaml e Berry (1985, 1988), também Dabholkar, Thorpe e Rentz (1996) sugerem que a qualidade percebida é determinada por cinco dimensões distintas. Entretanto as dimensões preconizadas foram: aspectos físicos que contam com duas subdimensões (aparência e conforto), confiabilidade, também com duas subdimensões (compromisso e assertividade), interações pessoais (subdividida em auxílio/cortesia e confiança), solução de problemas e políticas internas do varejista. Para Dabholkar, Thorpe e Rentz (1996), essas dimensões teóricas são determinantes para identificar a qualidade percebida do consumidor. A Figura 2 demonstra a definição operacional de cada dimensão propostas.

\begin{tabular}{|c|c|c|}
\hline Dimensão & Subdimensão & Definição operacional \\
\hline \multirow[t]{2}{*}{ Aspectos físicos } & Aparência & $\begin{array}{l}\text { Diz respeito à limpeza, a aparência geral, tanto da loja como } \\
\text { dos ambientes de apoio, disposição dos departamentos e } \\
\text { corredores. }\end{array}$ \\
\hline & Conforto & $\begin{array}{l}\text { Facilidade em localizar o produto desejado, facilidade de } \\
\text { mover-se pelos corredores e climatização da loja. }\end{array}$ \\
\hline \multirow[t]{2}{*}{ Confiabilidade } & Compromissos & $\begin{array}{l}\text { Honrar os compromissos e prazos negociados com os clientes } \\
\text { e manter no sortimento produtos de boa qualidade. }\end{array}$ \\
\hline & Assertividade & Esforçar-se para fazer certo na primeira vez. \\
\hline \multirow{2}{*}{ Interações Pessoais } & $\begin{array}{l}\text { Inspiração } \\
\text { confiança }\end{array}$ & $\begin{array}{l}\text { Os funcionários da loja devem inspirar confiança aos clientes. } \\
\text { Os clientes devem ter confiança nos esclarecimentos } \\
\text { prestados pelos funcionários da loja. }\end{array}$ \\
\hline & Auxílio e cortesia & $\begin{array}{l}\text { Os funcionários precisam demonstrar boa vontade e cortesia } \\
\text { quando os clientes necessitam de auxílio ou quando possuem } \\
\text { dúvidas. }\end{array}$ \\
\hline Solução de problemas & & $\begin{array}{l}\text { Diz respeito aos procedimentos adotados pelos varejistas } \\
\text { relativos às devoluções e trocas de produtos e como as } \\
\text { queixas são registradas e tratadas pelo varejista. }\end{array}$ \\
\hline Políticas internas & & $\begin{array}{l}\text { Política de aceitação de cartões de crédito e concessão de } \\
\text { crédito através de cartão próprio, horário de atendimento ao } \\
\text { público, disponibilidade de vagas nos estacionamentos. }\end{array}$ \\
\hline
\end{tabular}

Figura 2: Dimensões da qualidade segundo o modelo RSQ Fonte: Baseado em Dabholkar, Thorpe e Rentz (1996).

\subsection{Desenvolvimento da Escala RSQ}

A escala proposta por Dabholkar, Thorpe e Rentz (1996) é composta por 28 questões, dentre as quais 17 adaptadas da escala SERVQUAL e outras 11 foram desenvolvidas por meio da triangulação qualitativa realizada. Muito embora as dimensões das escalas RSQ e SERVQUAL sejam diferentes, os autores alegam que se sentiram confortáveis em utilizar 17 das 22 questões originais da escala SERVQUAL, pois essas foram baseadas em "extensas pesquisas qualitativas" desenvolvidas por Parasuraman, Zeithaml e Berry (1985).

A escala RSQ e suas afirmativas, comparadas com as dimensões da escala SERVQUAL, estão descriminadas na Figura 3.

\begin{tabular}{|c|c|c|c|}
\hline SERVQUAL & \multicolumn{2}{|c|}{ RSQ } & Afirmativa \\
\hline Dimensão & Dimensão & Subdimensão & \\
\hline Tangível & Aspecto Físico & Aparência & P1- Esta loja tem equipamentos e mobiliário modernos \\
\hline Tangível & Aspecto Físico & Aparência & $\begin{array}{l}\text { P2- Os ambientes de apoio da loja são visualmente } \\
\text { agradáveis }\end{array}$ \\
\hline Tangível & Aspecto Físico & Aparência & $\begin{array}{l}\text { P3- Os materiais relacionados a serviços (sacolas, } \\
\text { catálogos, impressos) são visualmente agradáveis. }\end{array}$ \\
\hline (NES) & Aspecto Físico & Aparência & $\begin{array}{l}\text { P4- A limpeza da loja, incluindo banheiros e salas de } \\
\text { descanso, é adequada. }\end{array}$ \\
\hline (NES) & Aspecto Físico & Conforto & $\begin{array}{l}\text { P5- O layout da loja facilita o cliente encontrar o que } \\
\text { necessita }\end{array}$ \\
\hline (NES) & Aspecto Físico & Conforto & P6- O layout da loja facilita a locomoção do cliente \\
\hline Confiança & Confiança & Compro & $\begin{array}{l}\text { P7- Quando a loja promete algo, cumpre dentro do } \\
\text { prazo informado. }\end{array}$ \\
\hline Confiança & Confiança & Compromisso & P8- A loja cumpre suas promessas. \\
\hline Confiança & Confia & Assertiv & $\begin{array}{l}\text { P9- A loja realiza os serviços de maneira correta na } \\
\text { primeira vez }\end{array}$ \\
\hline
\end{tabular}


Análise comparativa da escala RSQ (retail service quality) em diferentes formatos varejistas

Continuação...

\begin{tabular}{|c|c|c|c|}
\hline SERVQUAL & \multicolumn{2}{|c|}{ RSQ } & Afirmativa \\
\hline (NES) & Confiança & Assertividade & $\begin{array}{l}\text { P10- A loja mantém disponível as mercadorias que os } \\
\text { clientes desejam }\end{array}$ \\
\hline Confiança & Confiança & Assertividade & $\begin{array}{l}\text { P11- A loja esforça-se para manter os registros de } \\
\text { transações e dados sem erros }\end{array}$ \\
\hline Segurança & Interação Pessoal & $\begin{array}{c}\text { Inspiração de } \\
\text { confiança }\end{array}$ & $\begin{array}{l}\text { P12- Os empregados desta loja têm condições de sanar } \\
\text { as dúvidas dos clientes }\end{array}$ \\
\hline Segurança & Interação Pessoal & $\begin{array}{c}\text { Inspiração de } \\
\text { confiança }\end{array}$ & $\begin{array}{lllll}\begin{array}{l}\text { P13- } \\
\text { confiança comportamento dos clientes }\end{array} & & \text { funcionários inspira } \\
\text { contan }\end{array}$ \\
\hline Segurança & Interação Pessoal & $\begin{array}{c}\text { Inspiração de } \\
\text { confiança }\end{array}$ & $\begin{array}{l}\text { P14- O cliente se sente seguro em realizar transações } \\
\text { comerciais com esta loja }\end{array}$ \\
\hline Presteza & Interação Pessoal & Auxílio / Cortesia & 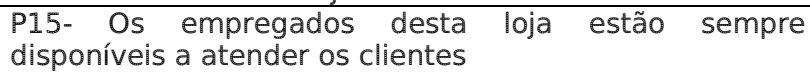 \\
\hline Presteza & Interação Pessoal & Auxílio / Cortesia & $\begin{array}{l}\text { P16- Os empregados desta loja prestam informações } \\
\text { corretas sobre os prazos em que os serviços serão } \\
\text { realizados }\end{array}$ \\
\hline Presteza & Interação Pessoal & Auxílio / Cortesia & $\begin{array}{l}\text { P17- Os empregados desta loja sempre estão } \\
\text { disponíveis para sanar as dúvidas dos clientes }\end{array}$ \\
\hline Empatia & Intera & Auxílio / & $\begin{array}{l}\text { P18- Esta loja dá atendimento personalizado aos seus } \\
\text { clientes }\end{array}$ \\
\hline Segurança & Interação Pessoal & Auxílio / Cortesia & P19- Os empregados desta loja sempre são cordiais \\
\hline (NES) & Interação Pessoal & Auxílio / Cor & $\begin{array}{l}\text { P20- Os empregados desta loja sempre são cordiais ao } \\
\text { telefone }\end{array}$ \\
\hline (NES) & Solução de problemas & - & P21- A loja facilita a troca e devolução das mercadorias \\
\hline Confiança & Solução de problemas & - & $\begin{array}{l}\text { P22- Quando o cliente tem um problema, a loja mostra } \\
\text { interesse sincero em resolver. }\end{array}$ \\
\hline (NES) & Solução de problemas & - & $\begin{array}{l}\text { P23- Os empregados da loja são habilitados a solucionar } \\
\text { pessoalmente as dúvidas e reclamações }\end{array}$ \\
\hline (NES) & lític & - & P24- Esta loja oferece produtos de alta qualidade \\
\hline (NES) & Políticas inte & - & P25- Esta loja disponibiliza amplo estacionamento \\
\hline Emp & P & - & $\begin{array}{l}\begin{array}{l}\text { P26- O horário de funcionamento desta loja é } \\
\text { conveniente para seus clientes }\end{array} \\
\end{array}$ \\
\hline (NES) & Polític & - & P27- A loja aceita a maioria dos cartões de crédito \\
\hline (NES) & Políticas internas & - & P28- A loja oferece seus próprios cartões de crédito \\
\hline
\end{tabular}

Nota: (NES) Não existe na escala SERVQUAL

Figura 3: Escala RSQ

Fonte: Dabholkar, Thorpe e Rentz (1996)

Os itens forma mensurados por meio de uma escala do tipo Likert de 5 pontos, ancorada em (1) discordo totalmente e (5) concordo totalmente.

\subsection{Validação da Escala RSQ}

Para validação dos construtos da escala RSQ, Dabholkar, Thorpe e Rentz (1996) realizaram uma aplicação empírica em sete lojas de varejo, pertencentes a duas redes distintas, localizadas no sudoeste dos Estados Unidos, que comercializavam produtos similares a públicos com perfis semelhantes.

A amostra contou com 227 respondentes, sendo 197 do sexo feminino com idade média de 43 anos, e 27 do sexo masculino com idade média de 40 anos.

Os questionários foram preenchidos pelos próprios clientes logo após sua visita à loja. Esta metodologia foi adotada pois, segundo Rust e Oliver (1994 apud Dabholkar, Thorpe, \& Rentz, 1996), entrevistar imediatamente após uma experiência de compra pode refletir com maior fidedignidade o nível de satisfação quanto à qualidade dos serviços. A pesquisa de campo durou três semanas e foi realizada durante todos os dias da semana abrangendo os períodos da manhã, tarde e noite.

Além das 28 questões da escala RSQ, os clientes foram interpelados sobre sua intenção de comprar (ou comprar novamente) naquela loja, bem como sobre a intenção de recomendar aquela loja a um amigo ou parente. A análise dos dados deu-se pela técnica de modelagem de equações estruturais.

Os índices de confiabilidade interna foram satisfatórios, com coeficientes Alfa de Cronbach entre 0,81 e 0,92 para as 5 dimensões e de 0,74 para a escala total. Segundo Dabholkar, Thorpe e Rentz (1996), a alta confiança registrada na escala sugere que a análise da qualidade de serviço foi conduzida apropriadamente, tanto ao nível das dimensões como ao nível das subdimensões, assim como na escala total. As validades convergente e discriminante foram verificadas e o modelo de mensuração, retratado na Figura 4, demonstrou que o modelo era robusto. 


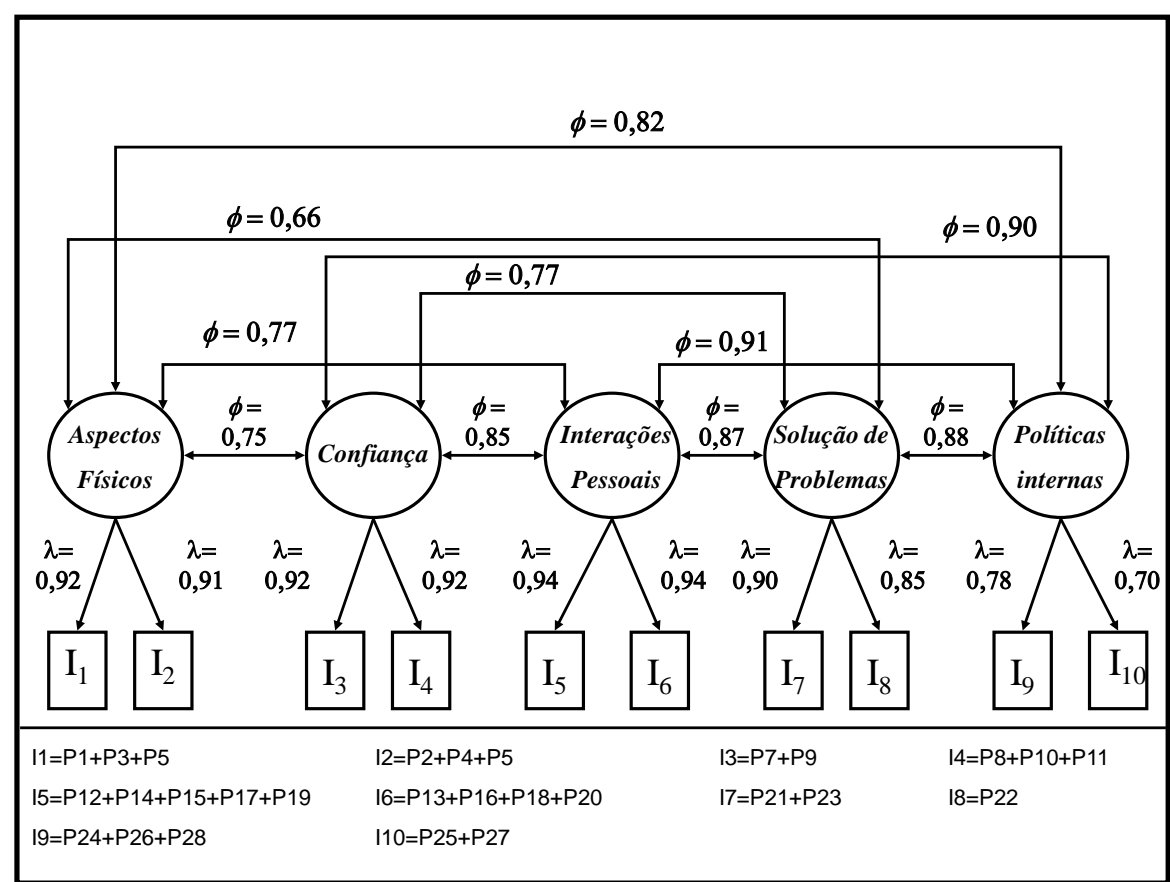

Figura 4: Validação do modelo RSQ

Fonte: Dabholkar, Thorpe e Rentz (1996, p. 12).

Mesmo não sendo uma prioridade na ocasião, verificou-se também a validade nomológica da escala proposta por Dabholkar, Thorpe e Rentz (1996) com identificação da relação entre as dimensões da qualidade e a intenção (de compra/recompra $\left.-r^{2}=0,65\right)$ e a recomendação $\left(r^{2}=0,70\right)$.

\subsection{Aplicações da Escala RSQ}

Blose, Tankersley e Flynn (1999) utilizaram a escala RSQ como instrumento de coleta de dados em uma pesquisa realizada durante seis semanas junto a 497 clientes de 13 diferentes lojas de alimentos da maior rede de supermercados do sudeste dos Estados Unidos. Relacionando as médias atribuídas pelos clientes para as cinco dimensões e respectivas subdimensões da escala com os dados de "produtividade" de cada loja - lucro sobre vendas e fluxo de clientes por hora de atendimento - foi possível estabelecer que as lojas com melhor desempenho eram as que possuíam maiores índices de qualidade de serviço, na avaliação dos clientes.

Questionando a adequabilidade dos atuais instrumentos para mensurar a percepção da qualidade de serviços de varejistas que atuam na distribuição de produtos técnicos, Mehta, Han, Lalwani, \& Mehta (1999) entrevistaram 300 clientes de lojas de produtos eletrônicos em diferentes Shopping Centers de Singapura. O questionário, que deveria ser retornado pelo correio, era dividido em duas seções. A primeira seção requisitava que os respondentes avaliassem a qualidade dos serviços de seu fornecedor de equipamentos eletrônicos preferido utilizando a escala RSQ e as 22 questões de percepção de qualidade da escala SERVQUAL. A segunda seção solicitava os dados do perfil sócioeconômico dos respondentes. Apenas 156 questionários foram respondidos de forma válida. Embora, na conclusão de seu trabalho, Mehta et al. (1999) propuseram uma nova escala para mensurar a percepção de qualidade em varejistas que trabalham intensivamente na comercialização de produtos técnicos, mencionaram que a escala RSQ teve melhor performance frente à escala SERVQUAL. No entanto ainda sugeriram novos estudos, pois as duas escalas, que foram validadas nos Estados Unidos, possuem alguns itens que não são relevantes para os varejistas de Singapura. Uma limitação apontada no estudo é o tamanho reduzido da amostra.

Yang, Peterson e Cai (2003) citaram outro estudo desenvolvido no Japão por Mehta et al em 2000. Nesse novo estudo foram testadas as escalas RSQ e SERVQUAL em dois grupos distintos de empresas varejistas. No primeiro, os varejistas apresentavam intensidade de serviços na configuração do negócio, enquanto que no segundo grupo o negócio era predominantemente alicerçado na comercialização de produtos. Mehta et al. (2000 apud Yang, Peterson, \& Cai, 2003) concluíram que a escala SERVQUAL é mais adequada na análise da qualidade de serviços percebida do primeiro grupo de empresas, enquanto a escala RSQ era mais eficiente no segundo grupo. 
Kim e Jin (2002) realizaram um estudo exploratório buscando determinar a validade da escala RSQ na mensuração da qualidade percebida de serviços em varejistas americanos e coreanos. Os pesquisadores aplicaram questionários em duas amostras. A primeira era composta por 214 estudantes universitários do leste dos Estados Unidos e a segunda era representada por 217 de duas universidades de Seul - Coréia. As amostras eram constituídas predominantemente por estudantes do sexo feminino ( $89,7 \%$ nos Estados Unidos e $82,5 \%$ na Coréia) e a grande maioria (55\% e 78,1\% respectivamente) havia realizado compras em lojas varejistas num intervalo máximo de uma semana da data preenchimento do questionário. A análise estatística da escala RSQ suportou as mesmas dimensões da qualidade nas duas amostras estudadas e sugeriu que os consumidores das duas culturas não fazem distinção entre as dimensões de interação pessoal e solução de problemas. Adicionalmente, a dimensão de políticas internas não foi observada em nenhum dos dois países.

Buscando entender a correlação das cinco dimensões da qualidade preconizadas por Dabholkar, Thorpe e Rentz (1996) com os construtos satisfação e confiança, Ramayah e Leen (2003) realizaram pesquisa com clientes de dois grandes varejistas do setor têxtil que operavam na Malásia. Foram aplicados 230 questionários tendo sido validados apenas 221.

Na conclusão do estudo, Ramayah e Leen (2003) alegaram que, geralmente, todas as 5 dimensões da qualidade identificadas no estudo de Dabholkar, Thorpe e Rentz (1996) podem influenciar na satisfação do consumidor. Alegaram também que a satisfação está mais ligada aos aspectos físicos e, em seguida, às dimensões de interação pessoal e política interna. Já o construto Confiança está fortemente correlacionado à dimensão da Confiabilidade e à dimensão de Solução de problemas. Os autores propuseram estudos complementares, pois, além da amostra utilizada ter sido muito pequena, 186 respondentes eram estudantes e, por consequência, 181 (ou seja, 85,8\% da amostra) não trabalhavam, o que, em última análise, resultou em um viés.

Apesar da aplicação da escala RSQ ter logrado êxito em pesquisas realizadas em países da África do Sul e em Singapura, tendo sido validada na análise da qualidade percebida de clientes dos segmentos varejistas de super e hipermercadistas e de lojas de departamento (Dabholkar, Thorpe \& Overby, 2005), Kaul (2005) realizou estudo para verificar a validade do instrumento quando aplicado em consumidores da cidade de Bangalore situada na Índia. A amostra foi definida pelo sistema de cotas utilizando como critérios de seleção o sexo, a renda e a idade dos respondentes identificados dentro da população amostral de clientes de grandes varejistas locais do segmento têxtil. Os dados foram coletados por entrevistadores que obtinham as informações nas residências dos respondentes. O levantamento de campo durou dois meses e, ao final deste período, foram coletadas 180 entrevistas, das quais 144 mostraram-se válidas. Os entrevistados expressavam sua percepção de qualidade de serviços através de uma escala de Likert de 7 pontos, para 26 das 28 questões originais da escala RSQ. A questão 20 (Os empregados desta loja sempre são cordiais ao telefone) e a questão 28 (A loja oferece seus próprios cartões de crédito) não foram aplicadas, pois esses padrões não são presentes na cultura varejista indiana. A análise estatística dos dados apontou a validade de apenas 3 das 5 dimensões propostas por Dabholkar, Thorpe e Rentz (1996). Somente as dimensões de Aspectos físicos, Solução de problemas e Políticas internas foram válidas para a amostra obtida. Kaul (2005) elenca algumas limitações da pesquisa que impedem sua generalização, dentre elas a pequena amostra estudada, a grande homogeneidade do universo amostral formado por habitantes da mesma cidade e frequentadores do mesmo perfil de loja e - a mais significativa para o pesquisador - a falta de adaptação da escala RSQ para a realidade do varejo indiano.

Meng, Summey, Herndon, \& Kwong (2009) aplicaram a escala RSQ em uma amostra formada por 400 clientes de uma importante rede supermercadista de Hong-Kong (China) que possui aproximadamente $70 \%$ do mercado local. Os pesquisadores utilizaram uma escala adaptada com apenas 18 dos 28 itens originais. O resultado apontou para 4 dimensões a qualidade percebida que explicaram $68,5 \%$ da variância da amostra. Os autores apontaram a grande diferença cultural entre o oriente e o ocidente como principal motivo para a utilização de apenas 18 itens da RSQ original e que esta decisão influenciou fortemente os resultados. Apontaram ainda que a parcimônia da escala é um dos seus grandes méritos.

\subsection{Aplicações da Escala RSQ no Brasil}

Lopes, Hernandez e Nohara (2009) compararam o resultado da mensuração da qualidade percebida por meio da RSQ e da SERVQUAL em uma amostra de 351 clientes de uma rede de lojas de materiais para construção civil. Além de não confirmarem a constituição teórica das 5 dimensões quando utilizam a 
SERVQUAL, os autores constataram superioridade da RSQ quando efetuaram o teste de validação nomológica. Enquanto a SERVQUAL justificava apenas $11 \%$ da variância da Lealdade da amostra, a RSQ foi capaz de explicar $43 \%$. Os autores reforçam a necessidade de novas aplicações da RSQ no cenário brasileiro sob duas alegações principais: a falta de estudos nacionais com o instrumento, haja vista a pesquisa realizada por eles ter sido a primeira iniciativa nacional e, em segundo lugar, mas não menos importante, a qualidade dos resultados obtidos por meio da aplicação da escala de Dabholkar, Thorpe e Rentz (1996).

A revisão da literatura permitiu o desenvolvimento da Figura 5 que sumariza, em uma linha temporal, as principais aplicações acadêmicas da escala RSQ.

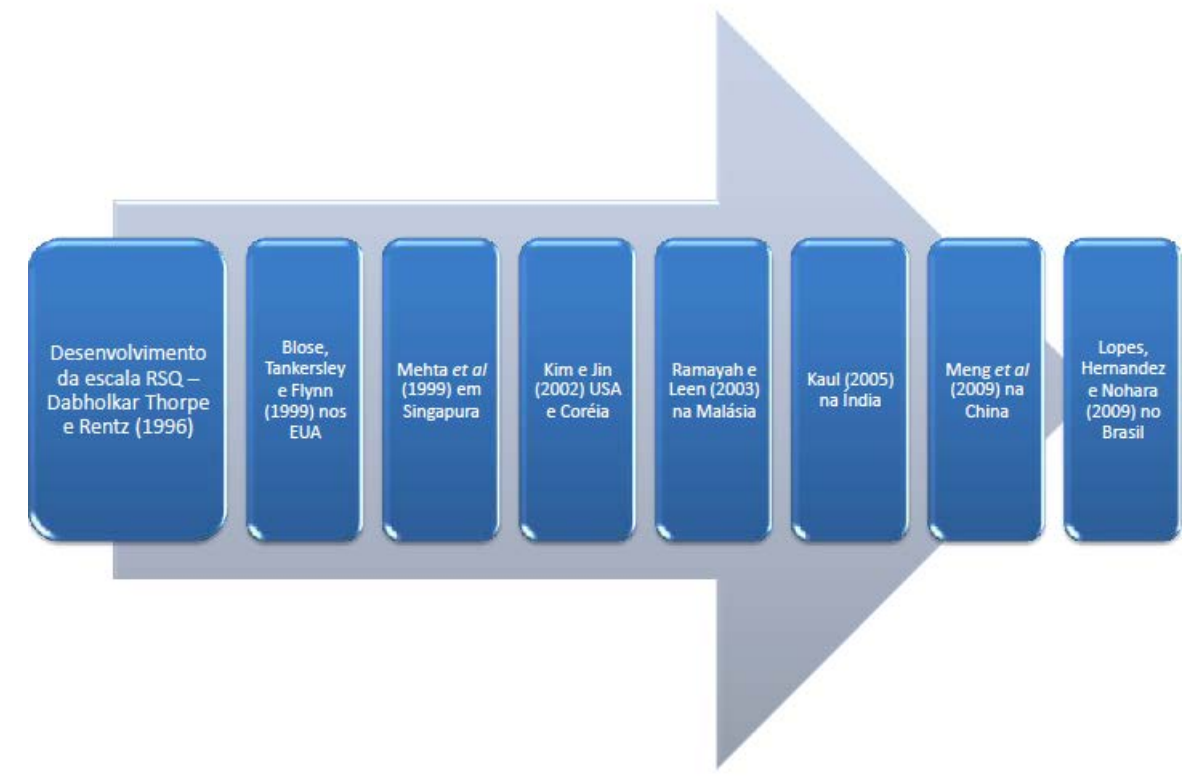

Figura 5: Principais aplicações da escala RSQ

Fonte: revisão bibliográfica

Por fim, ressalta-se que mesmo já tendo sido aplicada em diversos formatos varejista em quase uma dezena de países, desde sua criação em 1996, a escala RSQ mostrou-se confiável e eficaz naquilo que se propõe inclusive tendo desempenho superior a outras ferramentas mais tradicionais.

\section{Método}

O principal objetivo desta seção é evidenciar os procedimentos metodológicos que nortearam a etapa empírica deste estudo.

\subsection{Escalas}

Utilizou-se neste estudo a escala desenvolvida por Dabholkar, Thorpe e Rentz (1996) já nacionalizada. Como Lopes, Hernandez e Nohara (2009) realizaram a tradução reversa dos 28 itens da escala original e promoveram a validação de face dos mesmos com sucesso, utilizou-se nesta aplicação a mesma escala desses pesquisadores.

Assim como Dabholkar, Thorpe e Rentz (1996) e Lopes, Hernandez e Nohara (2009), a mensuração dos 28 itens foi feita por meio de uma escala do tipo Likert de 5 pontos, sendo 1 - Discordo totalmente e 5 Concordo totalmente.

\subsection{Amostra}

A coleta de dados foi realizada utilizando-se 3 amostras distintas formadas por consumidores de estabelecimentos varejistas. 
Foram entrevistados clientes de uma agência bancária, de uma loja de artigos esportivos e de uma loja de roupas. As duas lojas varejistas pertenciam a redes comerciais de atuação nacional e a agência bancária pertence a um grande banco multinacional que mantém operações em todos os estados do Brasil. A escolha por estes formatos deu-se pelo interesse dos pesquisadores em verificar a aplicação da escala RSQ em varejistas com diferentes perfis de atendimento, com variância dos níveis de serviços puros e de comercialização de produtos tangíveis e de diferentes níveis de envolvimento entre consumidores e varejistas.

A seleção dos entrevistados deu-se por conveniência o que resultou em uma amostra não probabilística (Hair, Anderson, Tatham, \& Black, 2009). Mesmo não permitindo a generalização dos dados, as amostras não probabilísticas são frequentemente utilizadas nas pesquisas em ciências sociais aplicadas (Cooper \& Schindler, 2003) devido, principalmente, ao baixo custo de sua obtenção (Cooper \& Schindler, 2003; Malhotra, 2006). Cooper e Schindler (2003) ressaltam que a validade deste tipo de amostra está basicamente associada ao pressuposto de que ela represente adequadamente a população que se pretende estudar. De fato, como a abordagem dos pesquisados se deu no próprio ambiente varejista, não há nada que indique baixa validade amostral. Assim como nesta aplicação, tanto o estudo original de Dabholkar, Thorpe e Rentz (1996) quanto o estudo de Lopes, Nohara e Hernandez (2009) utilizaram amostras não probabilísticas por conveniência. No primeiro, como já mencionado, foram pesquisados 227 clientes de sete lojas pertencentes a duas redes varejistas americanas e, no segundo, foram pesquisados 351 clientes em onze lojas de uma rede varejista paulista.

\subsection{Procedimentos}

Os entrevistados foram abordados na saída dos estabelecimentos comerciais utilizados como cenário para coleta dos dados. Todos os participantes eram maiores de 18 anos e haviam realizado uma operação comercial momentos antes da entrevista. Este cuidado foi tomado como forma de garantir que todos os entrevistados pudessem opinar sobre os atributos de qualidade do varejista analisado.

A abordagem foi realizada por entrevistadores treinados para esta tarefa. Após questionar se o entrevistado havia realizado alguma operação comercial (compra de material esportivo, compra de uma roupa ou transação bancária, conforme o caso) o entrevistador disponibilizava o questionário, em papel, para que o entrevistado indicasse sua avaliação dos 28 itens da escala RSQ em relação ao varejista ao qual acabara de utilizar.

A coleta de dados aconteceu entre Outubro de 2010 e Janeiro de 2011 na cidade de São Paulo.

\subsection{Plano de análise de dados}

Basicamente as técnicas de análise realizadas foram a estatística descritiva, por meio da análise de frequência das características demográficas da amostra, com utilização do software estatístico SPSS versão 15.0 e a modelagem de equações estruturais com auxílio do software SmartPLS 2.0M3 (Ringle, Wende, \& Will, 2005).

A modelagem de equações estruturais foi escolhida por permitir a avaliação das relações causais entre constructos e a subsequente avaliação dos coeficientes de caminho (Jöreskog \& Söbom, 1993) e também por ter sido a técnica utilizada no trabalho original de Dabholkar, Thorpe e Rentz (1996). Já a estimação por meio de PLS-PM (Partial Least Square - Path Modelling) ou Mínimos Quadrados Parciais Modelagem de Caminhos, que analisa a matriz de dados por correlação, foi escolhida por não prescindir de uma distribuição de dados normal, tampouco de grande número de observações, o que ocorre com os modelos Lisrel (Jöreskog \& Söbom, 1993; Chin, 1996).

A modelagem estrutural seguiu o método recomendado por Chin (1996). Inicialmente verificou-se a validade convergente dos indicadores, caracterizada por cargas superiores a 0,50 entre o indicador e construto, e a validade discriminante, por meio da comparação entre a raiz quadrada da AVE (variância média extraída) e o coeficiente de correlação entre os construtos.

\section{Resultados Observados}

O principal objetivo desta seção é demonstrar os resultados obtidos após a análise dos dados oriundos dos três surveys realizados. 


\subsection{Resultados do Estudo 1 - Agência Bancária}

A amostra do primeiro estudo foi composta por 262 respondentes, sendo 149 (56,9\%) mulheres e $113(43,1 \%)$ homens. A maior parte da amostra foi constituída por pessoas solteiras (135 respondentes ou $51,5 \%$ ) e com idade variando entre 18 e 30 anos (180 respondentes ou $69 \%$ ). A maioria dos respondentes informou possuir renda mensal de até três mil reais (148 respondentes ou 56,5\%).

\subsubsection{Validação do modelo do estudo 1}

$\mathrm{Na}$ primeira tentativa de modelagem dos dados do Estudo 1, percebeu-se a necessidade de eliminação de 5 indicadores do construto Interações Pessoais (P16, P17, P18, P19 e P20) pois todos apresentavam baixas cargas com o construto $(<0,50)$.

Na segunda tentativa, os indicadores demonstraram ajustes aceitáveis com os construtos, o que resultou em boa validade convergente. Passou-se então à análise da validade discriminante. Como pode ser visto na Tabela 1, as raízes da média da variância extraída dos construtos é maior que a correlação entre cada construto, comprovando a validade discriminante do modelo.

\begin{tabular}{|l|l|l|l|l|l|}
\hline \multicolumn{7}{|c|}{ Estudo 1 - Agência bancária } \\
\hline & $\begin{array}{l}\text { Aspectos } \\
\text { Físicos }\end{array}$ & Confiança & $\begin{array}{l}\text { Interações } \\
\text { Pessoais }\end{array}$ & Política Interna & $\begin{array}{l}\text { Solução } \\
\text { Problemas }\end{array}$ \\
\hline Aspectos Físicos & $\mathbf{0 , 6 2 1 1}$ & & & & \\
\hline Confiança & 0,3699 & $\mathbf{0 , 6 4 7 5}$ & & & \\
\hline Interações Pessoais & 0,2110 & 0,4208 & $\mathbf{0 , 7 0 2 3}$ & & \\
\hline Política Interna & 0,1037 & 0,1499 & 0,2186 & $\mathbf{0 , 6 8 0 5}$ & \\
\hline Solução de Problemas & 0,0826 & 0,1913 & 0,2149 & 0,2288 & $\mathbf{0 , 6 9 5 0}$ \\
\hline
\end{tabular}

Nota: As células da diagonal em destaque representam as raízes da AVE do construto.

Tabela 1: Validade discriminante do Estudo 1

\subsubsection{Modelagem estrutural do estudo 1}

Como demonstrado na Figura 6 , as cargas fatoriais dos indicadores ficaram entre 0,542 (P27 $\rightarrow$ Políticas Internas) e 0,760 (P21 $\rightarrow$ Solução de Problemas). Do mesmo modo, os coeficientes estruturais ficaram entre 0,436 (Solução de Problemas $\rightarrow$ RSQ) e 0,761 (Confiança $\rightarrow R S Q$ ). Todos os coeficientes estruturais se mostraram significantes $(p<0,01)$ sendo estimados por meio do teste de reamostragem bootstrap com 1000 repetições (Ringle, Wende, \& Will, 2005). Além disso, os coeficientes de determinação foram adequados variando entre $19 \%$ (Políticas Internas $r^{2}=0,19$ ) e $57 \%$ (Confiança $\left.r^{2}=0,579\right)$.

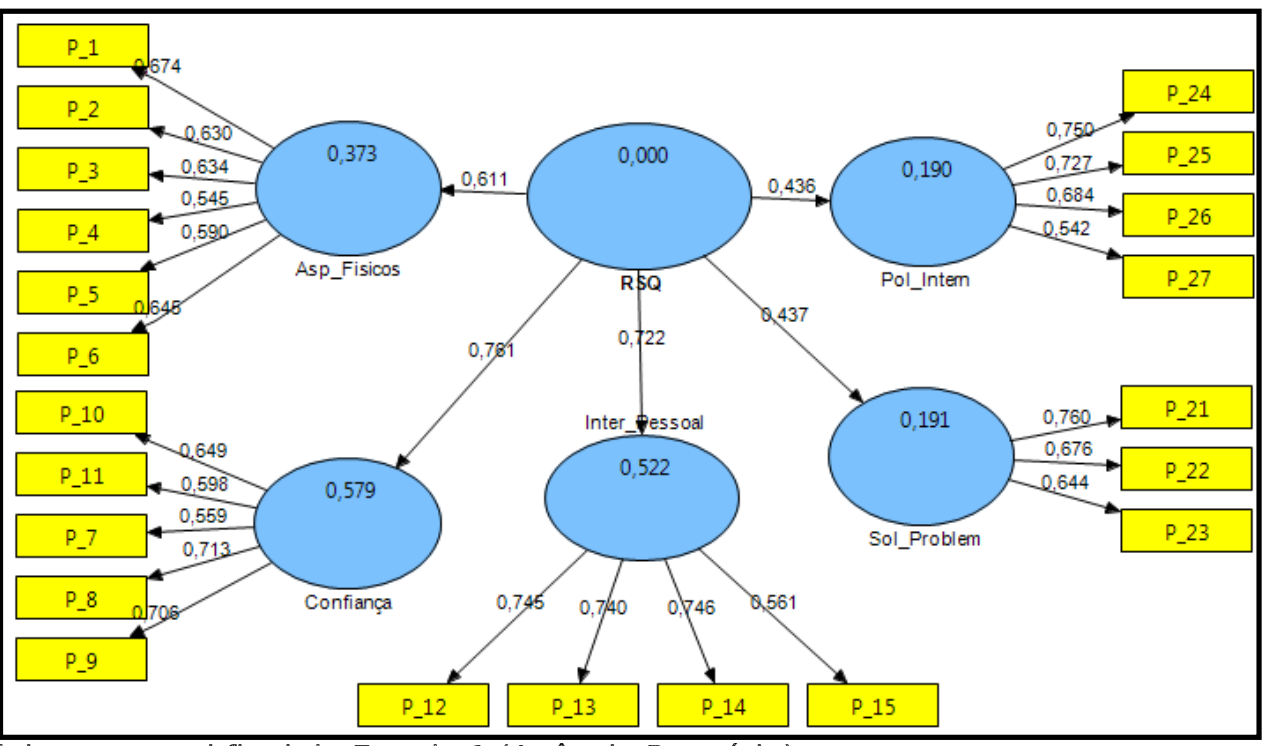

Figura 6: Modelo estrutural final do Estudo 1 (Agência Bancária) 


\subsubsection{Discussão dos resultados do estudo 1}

A escala RSQ mostrou-se adequada para mensuração da qualidade percebida no segmento de serviços bancários.

A eliminação de 5 indicadores da escala original não chegou a ser uma surpresa. A forte automação dos serviços bancários quer seja pelo uso de terminais de autoatendimento (ATMs) quer seja pela grande difusão da utilização da web para realização de qualquer tipo de operação, faz com o que a percepção de qualidade da interação pessoal, ou seja, do atendimento de uma agência bancária seja prejudicado. Este é um ponto interessante, pois a escala RSQ, aparentemente, não está preparada para mensuração de serviços ofertados pela web.

Por fim, o alto coeficiente de determinação do construto Confiança $\left(r^{2}=0,579\right)$ mostrou-se alinhado com estudos anteriores que demonstram que este construto é um dos atributos de maior relevância na avaliação dos serviços bancários (Hernandez \& Mazzon, 2008).

\subsection{Resultados do Estudo 2 - Loja de Artigos Esportivos}

A amostra do segundo estudo foi composta por 149 respondentes, sendo 87 (58,4\%) do sexo masculino e $62(41,6 \%)$ do sexo feminino. A maior parte da amostra foi constituída por pessoas solteiras (90 respondentes ou 60,4\%) e com idade variando entre 18 e 30 anos (78 respondentes ou 52,3\%). Do total, 113 respondentes $(75,8 \%)$ alegaram possuir curso superior concluído.

\subsubsection{Validação do modelo do estudo 2}

Na primeira tentativa de modelagem dos dados do Estudo 2, percebeu-se a necessidade de eliminação de 5 indicadores sendo 1 item do construto Confiança (P11), 1 item do construto Interações Pessoais (P14) e 3 itens do construto Políticas Internas (P24, P27 e P28), todos por baixa carga fatorial $(<0,50)$.

Na segunda tentativa, os indicadores demonstraram ajustes aceitáveis com os construtos, o que resultou em boa validade convergente. Passou-se então à análise da validade discriminante. Como pode ser visto na Tabela 2, as raízes da média da variância extraída dos construtos é maior que a correlação entre cada construto, comprovando a validade discriminante do modelo.

\begin{tabular}{|l|l|l|l|l|l|}
\hline \multicolumn{2}{|l|}{ Estudo 2 - Loja de Artigos Esportivos } \\
\hline & $\begin{array}{c}\text { Aspectos } \\
\text { Físicos }\end{array}$ & Confiança & $\begin{array}{c}\text { Interações } \\
\text { Pessoais }\end{array}$ & $\begin{array}{c}\text { Política } \\
\text { Interna }\end{array}$ & $\begin{array}{c}\text { Solução de } \\
\text { Problemas }\end{array}$ \\
\hline Aspectos Físicos & $\mathbf{0 , 6 7 6 8}$ & & & & \\
\hline Confiança & 0,5170 & $\mathbf{0 , 6 7 4 9}$ & & & \\
\hline Interações Pessoais & 0,4673 & 0,5985 & $\mathbf{0 , 6 7 2 5}$ & & \\
\hline Política Interna & 0,2769 & 0,2852 & 0,2642 & $\mathbf{0 , 7 6 9 2}$ & \\
\hline Solução de Problemas & 0,3604 & 0,3244 & 0,5627 & 0,5303 & $\mathbf{0 , 7 9 2 1}$ \\
\hline
\end{tabular}

Nota: As células da diagonal em destaque representam as raízes da AVE do construto Tabela 2: Validade discriminante do Estudo 2

\subsubsection{Modelagem estrutural do Estudo 2}

Como demonstrado na Figura 7, as cargas fatoriais dos indicadores ficaram entre 0,504 (P18 $\rightarrow$ Interações Pessoais) e 0,955 (P25 $\rightarrow$ Políticas Internas). Do mesmo modo, os coeficientes estruturais ficaram entre 0,495 (Políticas Internas $\rightarrow$ RSQ) e 0,878 (Interações Pessoais $\rightarrow$ RSQ). Todos os coeficientes estruturais se mostraram significantes $(p<0,01)$ sendo estimados por meio do teste de reamostragem bootstrap com 1000 repetições (Ringle, Wende, \& Will, 2005). Além disso, os coeficientes de determinação foram adequados variando entre $24 \%$ (Políticas Internas $r^{2}=0,245$ ) e 77\% (Interações Pessoais $r^{2}=0,771$ ). 


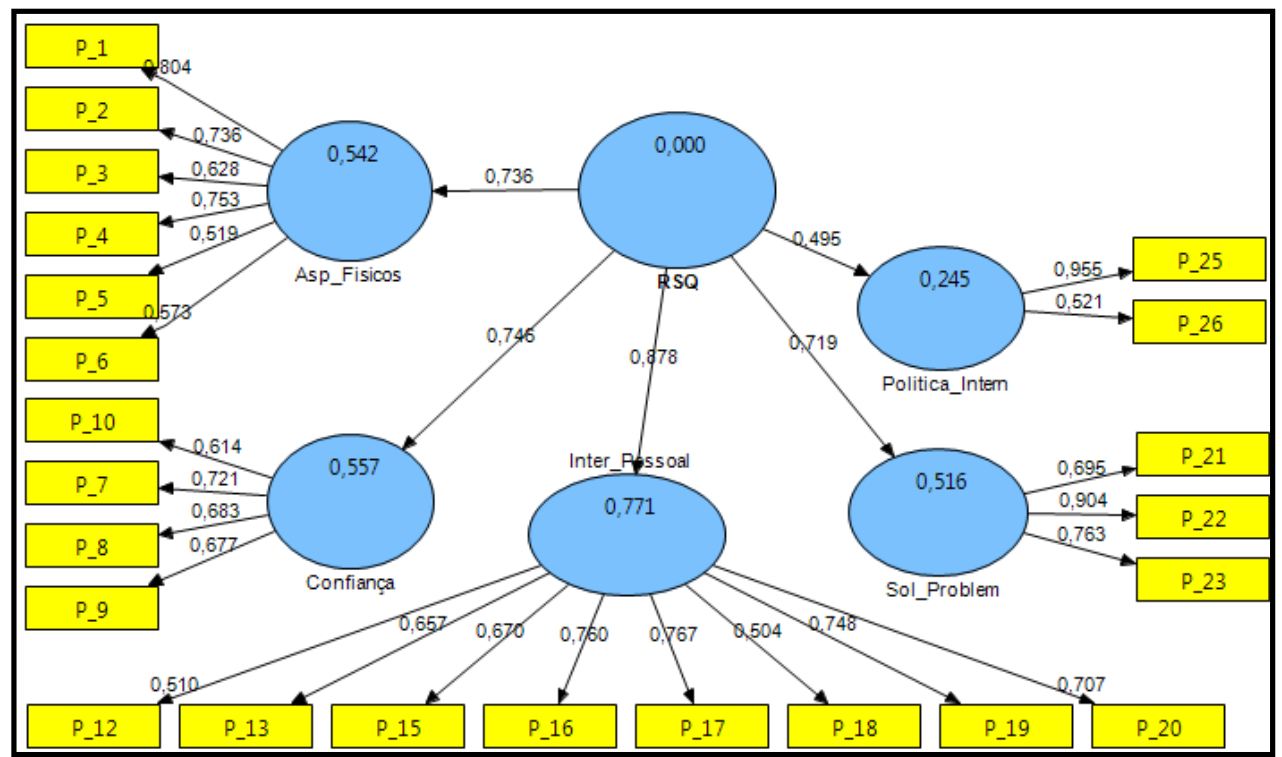

Figura 7: Modelo estrutural final do Estudo 2 (Loja de Artigos Esportivos)

\subsubsection{Discussão dos resultados do estudo 2}

Mesmo que a baixa comunalidade tenha indicado a necessidade da eliminação de 5 indicadores nesta aplicação, acredita-se que a escala desenvolvida por Dabholkar, Thorpe e Rentz (1996) seja adequada para mensuração da qualidade percebida neste formato varejista. Este entendimento está ancorado nos altos coeficientes de determinação verificados para todos os construtos (superiores a $50 \%$ ), exceto pelo construto Políticas Internas que ficou prejudicado pelo descarte de 3 indicadores.

O maior coeficiente de determinação foi verificado no construto Interações Pessoais $\left(r^{2}=0,771\right)$ o que indica a importância da qualidade do atendimento para a construção da imagem de alta qualidade de serviços neste formato varejista. Novamente o construto Confiança mostrou-se relevante na formação da imagem de qualidade $\left(r^{2}=0,557\right)$.

\subsection{Resultados do Estudo 3 - Loja de roupas}

A amostra do terceiro estudo foi composta por 247 respondentes, sendo 217 (87,9\%) mulheres e 30 $(12,1 \%)$ homens. A maior parte da amostra foi constituída por pessoas casadas (159 respondentes ou $64,4 \%$ ) e com idade variando entre 18 e 35 anos (149 respondentes ou 60,3\%). A maioria dos respondentes informou possuir renda mensal de até três mil reais (142 respondentes ou 57,5\%).

\subsubsection{Validação do modelo do estudo 3}

Na primeira tentativa de modelagem dos dados do Estudo 3, percebeu-se a necessidade de eliminação de 2 indicadores sendo 1 indicador do construto Confiança (P11) e outro do construto Políticas Internas (P28) ambos por baixa carga fatorial

\begin{tabular}{|l|l|l|l|l|l|}
\hline \multicolumn{6}{|l|}{ Estudo 3 - Loja de Roupas } \\
\hline & $\begin{array}{l}\text { Aspectos } \\
\text { Físicos }\end{array}$ & Confiança & $\begin{array}{l}\text { Interações } \\
\text { Pessoais }\end{array}$ & $\begin{array}{l}\text { Política } \\
\text { Interna }\end{array}$ & $\begin{array}{l}\text { Solução de } \\
\text { Problemas }\end{array}$ \\
\hline Aspectos Físicos & $\mathbf{0 , 9 1 4 7}$ & & & & \\
\hline Confiança & 0,7265 & $\mathbf{0 , 9 1 2 9}$ & & & \\
\hline Interações Pessoais & 0,6355 & 0,8194 & $\mathbf{0 , 8 6 5 2}$ & & \\
\hline Política Interna & 0,5253 & 0,6348 & 0,6147 & $\mathbf{0 , 7 1 4 9}$ & \\
\hline Solução de Problemas & 0,5073 & 0,7375 & 0,8370 & 0,6366 & $\mathbf{0 , 9 6 1 2}$ \\
\hline
\end{tabular}

Nota: As células da diagonal em destaque representam as raízes da AVE do construto

Tabela 3: Validade discriminante do Estudo 3 
Na segunda tentativa, os indicadores demonstraram ajustes aceitáveis com os construtos, o que resultou em boa validade convergente. Passou-se então à análise da validade discriminante. Como pode ser visto na Tabela 3, as raízes da média da variância extraída dos construtos é maior que a correlação entre cada construto, comprovando a validade discriminante do modelo.

\subsubsection{Modelagem estrutural do estudo 3}

Como demonstrado na Figura 8, as cargas fatoriais dos indicadores ficaram entre 0,597 (P25 $\rightarrow$ Políticas Internas) e 0,871 (P22 $\rightarrow$ Solução de Problemas). Do mesmo modo, os coeficientes estruturais ficaram entre 0,721 (Políticas Internas $\rightarrow$ RSQ) e 0,947 (Interações Pessoais $\rightarrow$ RSQ). Todos os coeficientes estruturais se mostraram significantes $(p<0,01)$ sendo estimados por meio do teste de reamostragem bootstrap com 1000 repetições (Ringle, Wende, \& Will, 2005). Além disso, os coeficientes de determinação foram bastante adequados variando entre 52\% (Políticas Internas $r^{2}=0,520$ ) e 89\% (Interações Pessoais $r^{2}=0,897$ ).

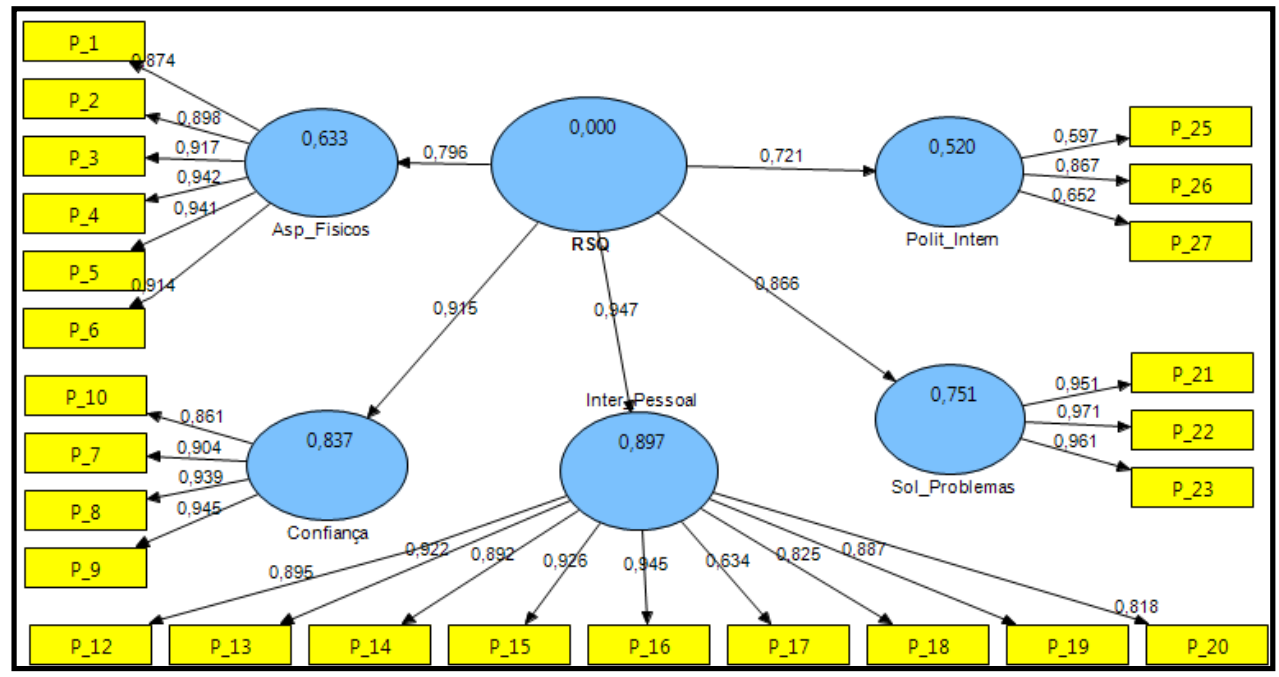

Figura 8: Modelo estrutural final do Estudo 3 (Loja de Roupas)

\subsubsection{Discussão dos resultados do estudo 3}

Novamente neste estudo, a escala RSQ mostrou-se adequada para mensuração da qualidade percebida no segmento varejista.

Também nesta aplicação, os coeficientes de determinação foram bastante elevados e todos os caminhos estruturais foram significantes $(p<1 \%)$.

Como no Estudo 2, os maiores coeficientes de determinação foram verificados nos construtos Interações Pessoais $\left(r^{2}=0,897\right)$ e Confiança $\left(r^{2}=0,837\right)$, mostrando uma clara tendência nos resultados.

\subsection{Discussão Geral}

Com o intuito de guiar a discussão agregada dos resultados dos três surveys realizados, formulou-se a Tabela 4, na qual constam os coeficientes de determinação de cada um dos construtos para cada estudo.

\begin{tabular}{|l|c|c|c|}
\hline \multicolumn{1}{|c|}{ Dimensão da RSQ } & Agência Bancária & Loja de Artigos Esportes & Loja de Roupas \\
\hline$\left(r^{2}\right)$ Aspectos Físicos & 0,373 & 0,542 & 0,633 \\
\hline$\left(r^{2}\right)$ Confiança & 0,579 & 0,557 & 0,837 \\
\hline$\left(r^{2}\right)$ Interações Pessoais & 0,522 & 0,771 & 0,897 \\
\hline$\left(r^{2}\right)$ Políticas Internas & 0,190 & 0,245 & 0,520 \\
\hline$\left(r^{2}\right)$ Solução de Problemas & 0,191 & 0,516 & 0,751 \\
\hline
\end{tabular}

Tabela 4: Coeficientes de determinação dos três estudos. 
Como pode ser visto na Tabela 4, a percepção de qualidade de serviços dos consumidores varejistas é em grande parte explicada pela Confiança e pelas Interações Pessoais que acontecem no ambiente varejista. Nos três formatos estudados estes foram os construtos que comungaram maior correlação com a qualidade percebida.

Se para o ambiente bancário, a importância da Confiança já era conhecida, para os demais formatos varejistas, o construto demonstrou-se também muito importante. Estudos recentes sobre o comportamento dos consumidores no e-commerce já apontaram para a grande preocupação dos varejistas com a Confiança demonstrada por seus clientes e como esse indicador pode afetar os negócios (Brei \& Rossi, 2005). Os resultados desta pesquisa sugerem que a preocupação varejista não deve ficar restrita apenas ao ambiente eletrônico. A Confiança dos consumidores explicou grande parte da qualidade percebida de serviços nos três formatos varejistas pesquisados e, em especial, no segmento de moda. Há indícios de que ser assertivo e manter bons produtos disponíveis para seus clientes, que é basicamente o cerne de uma operação varejista, ainda é uma das melhores estratégicas para formar a imagem de qualidade operacional e comercial. Também há indícios de que o grau de tangibilidade do produto comercializado não afeta a necessidade de manutenção da Confiança dos clientes.

Mesmo que os três formatos em estudo primem pelo sistema de autosserviço, no qual o cliente anda livremente e tem a possibilidade de servir-se sem a necessidade da intervenção de qualquer funcionário, o aspecto atendimento ainda é muito relevante para a formação da imagem de qualidade do varejista. Mesmo no ambiente bancário, no qual a automação já faz parte do cenário há muitos anos, o atendimento humanizado ainda é muito valorizado pelo cliente. Os resultados encontrados indicam que, apesar do autoatendimento resultar na ampliação da capacidade comercial de um estabelecimento varejista, é imprescindível que os gestores desse segmento primem pela manutenção do atendimento pessoal, investindo recursos na seleção e capacitação do pessoal da "linha de frente". Este resultado já era esperado na medida em que a dimensão sempre foi muito relevante na avaliação da qualidade percebida nos estudos anteriores. É certo que o varejo, como ambiente de trocas, necessita demande por contatos humanos entre clientes e empregados.

Aparentemente, os clientes não fazem muito distinção dos atributos físicos de uma agência bancária para outra, pois a variável não tem forte correlação com a qualidade percebida. O mesmo não pode ser dito dos formatos varejistas em que existe a aquisição de produtos tangíveis. Pode ser que um bom nível no aspecto físico de uma agência bancária seja condição sine qua non para os consumidores, pois existe a crença de que as organizações responsáveis pelas operações bancárias brasileiras são muito grandes, organizadas e lucrativas. Um achado deste estudo é o fato da dimensão dos Aspectos Físicos ser mais relevante para a loja de roupas que para os outros formatos estudados. Mesmo que o construto também seja relevante para a loja de artigos esportivos, aparentemente a qualidade percebida de uma loja de roupas é fortemente influenciada pela avaliação dos aspectos físicos da mesma. Outra possibilidade para o resultado é o perfil da amostra, predominantemente feminina, que tende a valorizar este atributo varejista. Embora a amostra utilizada por Dabholkar, Thorpe e Rentz (1996) seja predominantemente feminina $(86,7 \%)$ a dimensão dos Aspectos Tangíveis foi a de menor influência na formação da qualidade percebida de serviços, contudo, os autores não especificaram em qual segmento mercantil operava as duas redes de lojas pesquisadas.

Estranhamente, o coeficiente de determinação da dimensão Solução de Problemas foi muito diferente entre os 3 formatos e, em especial, na avaliação da qualidade da agência bancária. Uma possível explicação para este fenômeno é a baixa incidência de problemas vivenciados pelos respondentes. Uma análise post hoc identificou baixa variância da média dos 3 itens que mensuram o construto ( $M=4,18$; $\mathrm{dp}=0,16)$.

Aparentemente, existe maior influência na percepção de qualidade de serviços quando um varejista esforça-se em fazer certo na primeira vez do que quando ele se esforça para corrigir seu erro. A análise agregada dos estudos empíricos permite que se faça esta proposição quando se comparam os indicadores da Confiança e da Solução de Problemas.

A dimensão de Políticas Internas foi que teve menor influência na percepção de qualidade dos varejistas analisados. Se para a operação bancária este resultado já era esperado, pois algumas variáveis da dimensão fazem alusão à forma de pagamento de produtos disponibilizada aos clientes e também a adequação do horário de atendimento, que no caso das agências bancárias é padronizado, esperava-se que a dimensão fosse mais relevante para os dois formatos. O coeficiente de determinação da dimensão para a loja de roupas não chegou a ser baixo $(0,52)$, porém foi o menor dos cinco. Já para a loja de artigos 
esportivos, somente duas variáveis da dimensão foram significativas (horário de atendimento adequado e estacionamento amplo). Embora a loja analisada ofereça cartão de crédito próprio e aceite todos os cartões de crédito do mercado, aparentemente essas ações não estão sendo percebidas (ou valorizadas) pelos consumidores.

Finalmente, em linhas gerais, a escala RSQ mostrou bom ajustamento para os três formatos analisados sendo que poucos itens foram eliminados na construção dos modelos estruturais. Outro ponto favorável, que pode encorajar futuras aplicações acadêmicas e gerenciais da escala RSQ, é a confirmação da constituição multidimensional da qualidade percebida. Além disso, todos os construtos foram válidos e significantes.

\section{Considerações Finais}

O principal objetivo desta última seção é salientar as contribuições feitas por este estudo, identificar suas limitações e propor novas iniciativas acadêmicas para sequência desta linha de estudos.

\subsection{Contribuições Gerenciais}

Alguns fenômenos identificados neste trabalho podem servir para orientar os gestores de marketing e operadores varejistas. Inicialmente, a identificação da influência da Confiança na imagem de qualidade indica que os gestores devem redobrar a atenção na assertividade de suas estratégias de negócio, pois o consumidor parece pouco tolerante com os erros, mesmo que estes sejam corrigidos posteriormente.

A importância do pessoal de atendimento, que não chega a ser uma novidade para a área, reforça a necessidade de treinamento e capacitação do pessoal. Do mesmo modo que se investe em "tecnologia" de exposição de produtos que favoreçam o autoatendimento, deve-se investir no capital humano das organizações, pois estes são, aparentemente, mais valorizados que os atributos físicos de um varejista.

Do ponto de vista de comunicação, é recomendado que se reforce os planos de pagamento do estabelecimento, principalmente se estes foram diferenciados em relação aos concorrentes. Os operadores que já possuem estrutura para concessão de cartões de crédito próprio, devem buscar potencializar os benefícios embutidos neste produto financeiro com a introdução de algum programa de reconhecimento ou premiação por utilização. Aos operadores que ainda não possuem essa estrutura, recomenda-se que se realizem pesquisas no sentido de verificar se este serviço será percebido como um diferencial competitivo em relação aos demais concorrentes.

\subsection{Contribuições Acadêmicas}

A principal contribuição gerencial deste trabalho foi realizar uma análise comparativa da percepção da qualidade de serviços de três formatos varejistas distintos.

Com a utilização de uma ferramenta ainda pouco difundida no Brasil, foi possível verificar a influência das cinco dimensões teóricas na formação da qualidade percebida.

Como na maioria dos estudos anteriores, a escala RSQ mostrou-se parcimoniosa e de fácil aplicação, pois propõe a avaliação direta de seus 28 indicadores.

A identificação da forte influência da Confiança nos diferentes formatos analisados deve ser entendida como um avanço no estudo mercadológico.

Do ponto de vista científico, o estudo da qualidade percebida em serviços ainda está longe de ser esgotado. Espera-se que os resultados esta aplicação fomentem novas iniciativas no sentido de aumentar o arsenal de estudos sobre o tema o que possibilitará melhorar o entendimento diferenças perceptuais dos consumidores nos diferentes formatos organizacionais que disputam o mercado varejista.

\subsection{Principais Limitações e Sugestões para Estudos Futuros}

Entende-se como um limite deste estudo, o corte transversal na coleta de dados. Se por um lado esta técnica tenha proporcionado uma "foto do momento" no que se refere à percepção de qualidade dos 
consumidores dos três formatos varejistas pesquisados, por outro se torna uma limitação, pois não se percebe a mudança dessa mesma percepção no tempo. Sugere-se um estudo longitudinal, mesmo que com apenas um ou dois formatos para que se identifique como os fatores ambientais e temporais influenciam na percepção de qualidade.

Outro importante limitador deste trabalho foi a falta de adaptação de alguns itens para que retratassem melhor o formato varejista analisado. Para o caso da agência bancária, como praticamente inexiste a comercialização de produtos tangíveis, vários indicadores não foram validados. Neste sentido, a adaptação dos itens para um segmento de baixa tangibilidade seria uma contribuição relevante.

\subsection{Comentários Finais}

Grande parte dos estudos acadêmicos da qualidade percebida de serviços está voltada para a identificação ou desenvolvimento de escalas psicométricas que possibilitem sua mensuração, de forma confiável e parcimoniosa. Sob esse aspecto, acredita-se que a escala RSQ desenvolvida por Dabholkar, Thorpe e Rentz (1996) seja uma opção interessante para esse fim.

Mesmo considerando que nos últimos quinze anos já se contem diversas aplicações da escala RSQ no cenário internacional, ela ainda permanece pouco difundida no Brasil e o objetivo deste estudo foi, por meio da realização de três surveys, demonstrar sua aplicabilidade no contexto varejista nacional.

Neste sentido, ao avaliar-se a aplicação da escala, foi possível perceber que ela está habilitada para a mensuração da qualidade percebida de serviços no varejo brasileiro, pois, na comparação dos resultados obtidos na aplicação em uma agência bancária, em uma loja de artigos esportivos e em uma loja de roupas, foi possível identificar as cinco dimensões da qualidade preconizadas por Dabholkar, Thorpe e Rentz (1996) além de verificar os pontos de maior e menor relevância para cada formato varejista.

Este reflexão permite inferir que o objetivo da pesquisa foi alcançado e mesmo que a escala passe por adaptações no sentido de atender as necessidades de cada tipo de varejo, os resultados acabaram refletindo seus pontos fortes e fracos.

As principais contribuições acadêmicas deste estudo foram a ampliação do debate sobre a qualidade percebida em serviços e o aprofundamento do entendimento sobre uma ferramenta de mensuração ainda pouco aplicada.

De fato, após a revisão da literatura sobre o tema, ficou evidente aos autores que existe grande interesse sobre o assunto, especialmente no contexto varejista. Contudo, ainda não há um consenso estabelecido, pois faltam estudos que esgotem o tema de forma sistemática. Espera-se que este trabalho tenha contribuído, mesmo que modestamente, para o entendimento da percepção de qualidade no setor varejista.

\section{Notas}

1- Os autores agradecem ao FAP-Fundo de Apoio à Pesquisa da Universidade Nove de Julho/SP.

2- Pesquisas realizadas no Schollar Google e na base EBSCO em 09 de Abril de 2011 compreendendo os trabalhos disponibilizados a partir de janeiro de 2009.

\section{Referências}

Beinstock, C.C., Mentzer, J. T., \& Bird, M.M. (1997). Measuring physical distribution service quality. Journal of the Academy of Marketing Science, 25(1), 31-44. doi: 10.1007/BF02894507

Blose, J.E., Tankersley, W.B., \& Flynn (1999). Managing service quality using data envelopment analysis. Journal QMJ on line, 12(2),

Brei, V. A., \& Rossi, C. A.V. (2005). Confiança, valor percebido e lealdade em trocas relacionais de serviço: um estudo com usuários de Internet Banking no Brasil. Revista de Administração Contemporânea, 9(2), 145-168. http://dx.doi.org/10.1590/S1415-65552005000200008 
Carman, J.M. (1990). Consumer perceptions of service quality: An assessment of the SERVQUAL dimensions. Journal of Retailing, 66 (1), 33-55. doi: 10.1016/S0148-2963(99)00084-3

Chin, W.W. (1996). Partial least squares is to Lisrel as principal components analysis is to common factor analysis. Tecnology Studies, 2 (1), 315-319.

Cooper, D. R. \& Schindler, P. S. (2003). Métodos de pesquisa em administração. Porto Alegre: Bookman.

Cronin, J. \& Taylor, S. (1992). Measuring Service Quality: a reexamination and extension. Journal of Marketing, 56 (3), 55-68. doi: 10.2307/1252296

Dabholkar, P.A., Thorpe, D.I., \& Overby, J.W. (2005). Linking process and outcome to service quality and customer satisfaction evaluations. International Journal of Service Industry Management, 16(1), 10-27. doi 10.1108/09564230510587131

Dabholkar, P.A., Thorpe, D.I., \& Rentz, J.O. (1996). A measure of service quality for retail stores: scale development and validation. Journal of the Academy of Marketing Science, 24(1), 3-16.doi:

$10.1177 / 009207039602400101$

Finn, D.W. \& Lamb, C.W. (1991). An evaluation of the SERVQUAL scales in retail setting, Advances in Consumer Research, 18(2), 483-490.

Guiry, M., Hutchinson, W., \& Weitz, B.A. (1992). Consumer's Evaluation of Retail Store Service Quality and Its Influence on Store Choice, Working paper, University of Florida.

Hair, J. F., Anderson, R. E., Tatham, R. L., \& Black, W. C. (2009) Análise Multivariada de Dados. 6.ed. Porto Alegre: Bookman.

Hernandez, J.M.C. \& Mazzon, J.A. (2008). Um estudo empírico dos determinantes da adoção de internet banking entre não usuários brasileiros. Revista de Administração Contemporânea, 12(edição especial), 9 39.

Hong, S. \& Goo, Y.J.J. (2004). A causal model of customer loyalty in professional service firms: an empirical study. International Journal of Management, 21(4), 531-540.

Jöreskog, K. \& Söbom, D. (1993). Structural Equation Modeling with the SIMPLES Command Language. Lincolnwood: SSI.

Kaul, S. (2005). Measuring retail service quality: examining applicability of international research perspectives in India. Indian Institute of Management, Ahmedabad-India, Research and Publications.

Kim, S. \& Jin, B. (2002). Validating the retail service quality scale for US and Korean customers of discount stores: an exploratory study. Journal of Services Marketing, 16(3), 223-237. doi:

$10.1108 / 08876040210427218$

Lopes, E. L., Hernandez, J. M. C, \& Nohara, J. J. (2009). Escalas concorrentes para a mensuração da qualidade percebida: uma comparação entre a Servqual e a RSQ. Revista de Administração de Empresas, São Paulo, 49(4), 401-416. doi 10.1590/S0034-75902009000400004.

Malhotra, N.K.(2006). Pesquisa de Marketing: uma orientação aplicada. 4. ed. Porto Alegre: Bookman.

Mehta, S.C., Han, S., Lalwani, A.K., \& Mehta, S.S. (1999). Service quality of retailers distributing technical products: an extension. International Journal of Retail \& Distribuition Management, 28(2), 62-72.

Meng, J., Summey, J. H., Herndon, N. C., \& Kwong, K. K. (2009). Some retail service quality expectations of Chinese shoppers. International Journal of Market Research, 51(6), 773-796.

Parasuraman, A., Zeithaml, V. A., \& Berry, L. L. (1985). A conceptual model of Service Quality: Its implications for future research. Journal of Marketing, 28(2), 41-50. doi: 10.2307/1251430

Parasuraman, A., Zeithaml, V. A., \& Berry, L. L. (1988). SERVQUAL: A multiple item, scale for measuring consumer perceptions of service quality. Journal of Retailing. 64(2), 12-40.

Ramayah, T. \& Leen, J.Y.A. (2003). What drives relationship quality? A study of two retail clothing stores. $5^{\text {th }}$ Asian Academy of Management Conference, "Challenges of Globalized Business: The Asian Perspective", Malaysia, $10^{\text {th }}-13^{\text {th }}$ September. 
Ringle, C.M., Wende, S., \& Will, A. (2005). SmartPLS 2.0 M3 (beta). Germany: University of Hamburg, 2005. Disponível em: <http://www.smartpls.de>. Acesso em: 18 Nov 2010.

Sharma, S., Netemeyer, R.G., \& Mahajan, V. (1990). Search of excellence revisited: an empirical evaluation of Peters and Waterman's attributes of excellence. In: William O. Bearden and A. Parasuraman (Eds). Enhancing knowledge development in marketing, Chicago: American Marketing Association, pp. $322-328$.

Sujan, H, Weitz, B.A., \& Kumar, N. (1994). Learning Orientation, Working Smart, and Effective Selling. Journal of Marketing, 58(3), 39-52. doi: 10.2307/1252309

Yang, Z., Peterson, R.T., \& Cai, S. (2003). Services quality dimensions of internet retailing: an exploratory analysis. Journal of Service Marketing, 17(7), 685-700. doi: 10.1108/08876040310501241 